The Journal of Vitaminology 5, 254-260 (1959)

\title{
METABOLISM OF RIBOFLAVIN BY ANIMAL TISSUES
}

\author{
SHIN WATANABE \\ National Sanatorium, Toneyama Hospital, Toyonaka, Osaka
}

(Received June 23, 1959)

\begin{abstract}
When mice were loaded with riboflavin, and the homogenate of their whole body was subjected to paper chromatography in the course of the study on the metabolism of riboflavin, an unknown spot was discovered on the chromatogram, and it was identified as riboflavinyl-glucoside. The glucoside was further recognized as the precursor of flavin-adenine dinucleotide (FAD). Thus the following new phosphorylation process in vivo of riboflavin was elucidated: Riboflavin $\rightarrow$ riboflavinyl-glucoside $\rightarrow$ FAD. Few papers clarifying the phosphorylation of riboflavin in animal tissues are available. Whitby $(1,2)$ described an in vitro experiment only, wherein riboflavinyl-glucoside was produced from riboflavin by the action of a raw protein solution obtained from the acetone powder of rat livers and the glucoside was proved to have been produced from riboflavin and maltose.
\end{abstract}

\section{EXPERIMENTAL}

Method - A whole body of a mouse weighing about $20 \mathrm{~g}$, fed Oriental Pellet Diet Mc 5, was homogenized in a mixer, and was separated into various types of riboflavin by means of paper chromatography after deproteinization (3). The amount of riboflavin was determined by lumiflavin fluorometry, utilizing a fluoromicrometer (4).

Condition of Paper Chromatography — A descending method using Toyo filter paper No. 131 was used at $22^{\circ}$. Flow rate: $30-32 \mathrm{~cm} / 8 \mathrm{hr}$. Developer: Supernatant of the solution of the butanol, acetic acid and water-saturated isoamyl alcohol $(4: 1: 5)$.

The amounts of riboflavin, flavin mononucleotide (FMN) and FAD used for this experiment are all expressed by the equivalent values of riboflavin.

\section{RESULTS}

\section{Separation of Riboflavinyl-Glucoside by Use of a Resin}

After removing fat with acetone and ether from Amberlite 400 of 100200 mesh, $N \mathrm{NaOH}$ was passed through the resin, which was then washed with water, followed by $N \mathrm{HCl}$ and rinsing, and the test solution (pH 9.0) was flowed through, whereby each type of riboflavin was adhered to the resin. 
Hydrochloric acid of various concentrations is used one after another from the weak to the strong in that order for dissolving the adherents out. As shown in Table I, riboflavinyl-glucoside was dissolved out by $N / 50 \mathrm{HCl}$.

TABLE I

Separation of Riboflavinyl-Glucoside by Means of Ion Exchange Resin

\begin{tabular}{ccccc}
\hline \multicolumn{5}{c}{ Type of riboflavin derivatives detected } \\
Ribl & Riboflavin & $\begin{array}{l}\text { Riboflavinyl- } \\
\text { glucoside }\end{array}$ & FMN & FAD \\
\hline$N$ & + & & & \\
$1 / 200$ & + & + & & \\
$1 / 100$ & & & + & + \\
$1 / 50$ & & & & \\
$1 / 10$ & & & & \\
$1 / 5$ & & & & \\
\hline
\end{tabular}

The solution was then concentrated, and was recrystallized from alcohol.

\section{Determination of Riboflavin}

$R_{\mathrm{F}}$ Values Obtained with Various Solvent Systems - As shown in Table II, the $R_{F}$ values of riboflavinyl-glucoside found in this experiment were in fair

TABLE II

$R_{\mathrm{F}}$ Values Obtained with Various Solvent Systems

\begin{tabular}{ccc}
\hline Solvent system & Values found & Values from references \\
\hline A & 0.20 & 0.22 \\
B & 0.60 & 0.60 \\
C & 0.41 & 0.40 \\
\hline
\end{tabular}
A, n-Butanol-acetic acid-water $(4: 1: 5)$. Supernatant was used.
B, n-Butanol-phenol-water $(30 \mathrm{ml}: 160 \mathrm{~g}: 100 \mathrm{ml})$. Bottom layer was used.
C, $5 \% \mathrm{Na}_{2} \mathrm{HPO}_{4}$.

agreement with those obtained from the livers of rats by Whitby and also with those found by Hennekens. Only one spot was obtained when the above two substances taken from different sources, were mixed, and developed.

Absorption Spectrum - The absorption spectrum had, as shown in Fig. 1, three maximum values at 270 , 367 and $444 \mathrm{~m} \mu$.

Detection of Glucose - Riboflavinyl-glucoside solution was hydrolyzed with $N \mathrm{HCl}$ at $100^{\circ}$ for 2.5

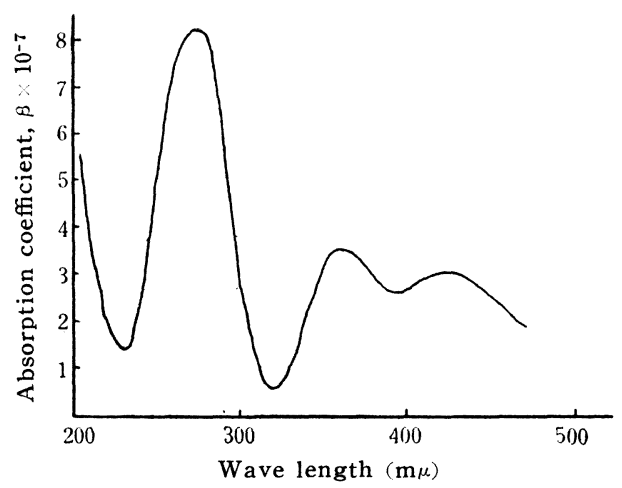

Fig. 1 Absorption Spectrum of RiboflavinylGlucoside 
hours, lyophilized in vacuo, and the residue was dissolved in a small amount of water. The solution was subjected to paper chromatography, and the development was carried out with the supernatant solution of butanol-acetic acid-water $(4: 1: 5)$. Glucose liberated in this way was then detected using aqueous ammoniacal solution of silver nitrate.

3. Types of Riboflavin in Mouse Body-As shown in Table III, the total amount of riboflavin in the body of a mouse averaged $4.43 \mu \mathrm{g} / \mathrm{g}$. There existed only FMN and FAD, no free riboflavin being detected.

TABLE III

Amount of Riboflavin per $g$ of Mouse

The figures are the averages of 10 specimens.

\begin{tabular}{lccc} 
& Total riboflavin & FMN & FAD \\
\hline Average value & $\mu \mathrm{g} / \mathrm{g}$ & $\mu \mathrm{g} / \mathrm{g}$ & $\mu \mathrm{g} / \mathrm{g}$ \\
Maximun value & $\mathbf{4 . 4 3 + \mathbf { 0 . 4 5 }}$ & $\mathbf{1 . 5 6}+\mathbf{0 . 2 1}$ & $\mathbf{2 . 6 6} \mathbf{0 . 4 1}$ \\
Minimum value & 5.2 & 1.83 & 3.43 \\
& 3.7 & 1.36 & 2.34 \\
\hline
\end{tabular}

4. Riboflavinyl-Glucoside as an Intermediate Product of FAD Formation from Riboflavin in Living Bodies

Detection of Riboflavinyl-Glucoside in Paper Chromatogram In the paper chromatogram of the whole body homogenate of an untreated mouse, riboflavinyl-glucoside was never detected. The glucoside, however, did appear, when paper chromatography was conducted with the whole body homogenate of a mouse prepared immediately after loading with riboflavin.

Participation of ATP in the Formation of Riboflavinyl-Glucoside After loading with $40 \mu \mathrm{g} / \mathrm{g}$ of riboflavin plus ATP, the formation of riboflavinylglucoside reached its maximum when 5 times as much ATP was used as riboflavin on a molar basis. Thus riboflavinyl-glucoside is known to be derived from riboflavin in the presence of ATP (Table IV).

\section{TABLE IV \\ Influence of $A T P$}

The figures indicate $\mu \mathrm{g} / \mathrm{g}$. The same is applicable in the following Tables.

\begin{tabular}{crcccc} 
& \multicolumn{4}{c}{ Type of riboflavin derivatives detected $(\mu g / g)$} \\
Riboflavin & ATP & Riboflavin & $\begin{array}{l}\text { Flavinyl- } \\
\text { glucoside }\end{array}$ & FMN & FAD \\
\hline & & & & & \\
40 & 60 & 27.38 & 4.22 & 2.53 & 6.33 \\
40 & 300 & 18.04 & 9.02 & 1.00 & 9.63 \\
40 & 1200 & 34.29 & 2.31 & 3.45 & 8.05 \\
\hline
\end{tabular}

Behavior of Each Type of Riboflavin During 24 Hours after Loading with Riboflavin - After loading with $40 \mu \mathrm{g} / \mathrm{g}$ of riboflavin and plus $250 \mu \mathrm{g} / \mathrm{g}$ of 
ATP, riboflavin was detected for 15 hours, and riboflavinyl-glucoside for about 8 hours. Parallel relations appeared to be present among the amounts of riboflavin, riboflavinyl-glucoside, and FAD at each time, possibly suggesting that the glucoside might be the precursor of FAD (Fig. 2).

Formation of FAD from Riboflavinyl-Glucoside — Immediately after loading with 10,20 and 40 $\mu \mathrm{g} / \mathrm{g}$, respectively, of riboflavinyl-

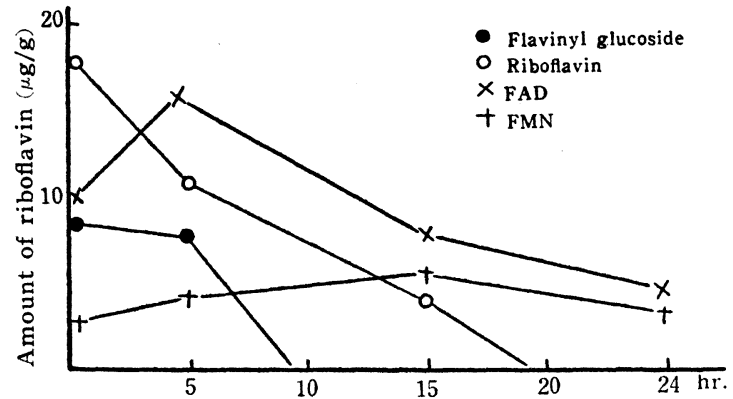

FIg. 2 Behavior of Each Riboflavin Fraction during 24 Hours after Loading with Riboflavin Together with ATP glucoside, the amount of each type of riboflavin was measured. The amount of FAD was found to rise in parallel with that of the glucoside (Table V).

TABLE V

Amounts of Riboflavin Derivatives Immediately after Loading with Riboflavinyl-Glucoside

\begin{tabular}{lccc}
\hline & \multicolumn{3}{c}{ Loaded with flavinyl-glucoside $(\mu g / g)$} \\
Type of riboflavin & 10 & 20 & 40 \\
\hline Riboflavin & 0 & 0 & 0 \\
Flavinyl-glucoside & 2.6 & 4.5 & 22.8 \\
FMN & 7.6 & 9.9 & 6.8 \\
FAD & 5.5 & 9.6 & 14.4 \\
\hline
\end{tabular}

Influence of ATP on the Formation of FAD - When $40 \mu \mathrm{g} / \mathrm{g}$ of riboflavinylglucoside was loaded together with ATP, FAD was found to rise with the increase of ATP (Table VI).

5. Relationship between FMN and Riboflavin, and That between FMN and FAD

Loading with FAD - Whatever amount of FAD being loaded, riboflavinyl-glucoside was never detected. Riboflavin was detected only when large amount of FAD was loaded. However, FMN was detected in great amount.

On the Types of Riboflavin in Living Bodies Immediately after Loading with

TABLE VI

Effect of ATP Loaded Together with Flavinyl-Glucoside

\begin{tabular}{lccc}
\hline & \multicolumn{3}{c}{ Times moles of ATP loaded } \\
\cline { 2 - 4 } & 0 & 1 & 5 \\
\hline Riboflavin & 0 & 0 & 0 \\
Flavinyl-glucoside & 19.9 & 18.9 & 18.0 \\
FMN & 5.9 & 4.1 & 5.7 \\
FAD & 12.6 & 14.9 & 16.2 \\
\hline
\end{tabular}


TABLE VII

Amount of Riboflavin Immediately after Loading with FAD

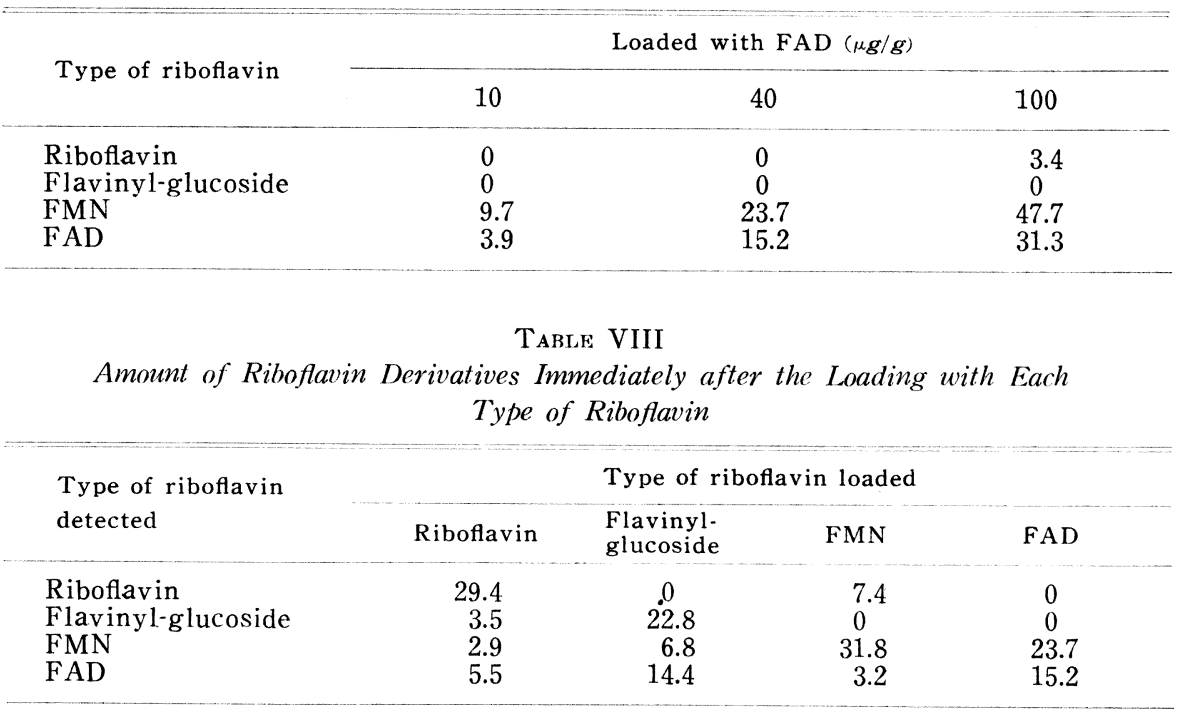

Each Type of Riboflavin - The experiment was carried out by loading with riboflavin, riboflavinyl-glucoside, FMN and FAD, respectively, with the results given in Table VIII. When riboflavin alone was loaded, all four types of riboflavin made its appearance. After loading with riboflavinyl-glucoside, riboflavin failed to be recognized. After loading with FMN, riboflavinylglucoside was not found. After loading with FAD, both riboflavin and riboflavinyl-glucoside failed to be detected. Furthermore, from the finding that the formation of FAD was conspicuous after loading with riboflavinylglucoside, and the value of FAD was almost the same as after loading with FAD itself, it was deduced that riboflavinyl-glucoside might be a precursor of FAD.

\section{DISCUSSION}

From the above findings, it is clear that the unknown spot discovered on the paper chromatogram of the whole body homogenate of a mouse loaded with riboflavin is riboflavinyl-glucoside. If the degradation of each type of riboflavin occurs rapidly in the body after loading, it causes a trouble in following the fate of the vitamin. Measurements of the amount of each type of riboflavin in the bodies of mice together with excrement and urine were therefore made at proper intervals after loading with each type of riboflavin. The experiment showed that in each case the sum of the measured amount was constant. It is therefore evident that each type of riboflavin is not degraded in the bodies of mice (Table IX).

Although in the case of FAD formation from riboflavinyl-glucoside, FAD 
TABLE IX

Degradation of Riboflavin in the Body

\begin{tabular}{|c|c|c|c|c|c|}
\hline \multirow{2}{*}{$\begin{array}{l}\text { Type of } \\
\text { riboflavin }\end{array}$} & \multirow{2}{*}{$\begin{array}{l}\text { Specimen } \\
\text { tested }\end{array}$} & \multirow{2}{*}{$\begin{array}{l}\text { Immediately } \\
\text { after loading }\end{array}$} & \multicolumn{3}{|c|}{ Time after loading (min) } \\
\hline & & & 15 & 30 & 45 \\
\hline \multirow{3}{*}{ Riboflavin } & \multirow{3}{*}{$\begin{array}{l}\text { Body } \\
\text { Excrement } \\
\text { and urine } \\
\text { Total }\end{array}$} & 43.3 & 29.8 & 24.4 & 31.3 \\
\hline & & & 14.3 & 17.2 & 15.0 \\
\hline & & 43.3 & 44.1 & 41.6 & 46.3 \\
\hline \multirow{3}{*}{ FMN } & \multirow{3}{*}{$\begin{array}{l}\text { Body } \\
\text { Excrement } \\
\text { and urine } \\
\text { Total }\end{array}$} & 40.3 & 39.2 & 39.7 & 43.1 \\
\hline & & & & 11.6 & 0.5 \\
\hline & & 40.3 & 39.2 & 51.3 & 43.6 \\
\hline \multirow{3}{*}{ FAD } & \multirow{3}{*}{$\begin{array}{l}\text { Body } \\
\text { Excrement } \\
\text { and urine } \\
\text { Total }\end{array}$} & 46.2 & & 43.9 & 49.9 \\
\hline & & & & & 0.2 \\
\hline & & 46.2 & & 43.9 & 50.1 \\
\hline
\end{tabular}

formation is increased in parallel with the increase of the glucoside, the situation is not necessarily consistent, when the amount of the glucoside is very great, suggesting some roles played by ATP in this process as shown in Table VI. It is then assumed that FAD and glucosephosphate are formed from riboflavinyl-glucoside and ATP in the body of a mouse as shown in Fig. 3.

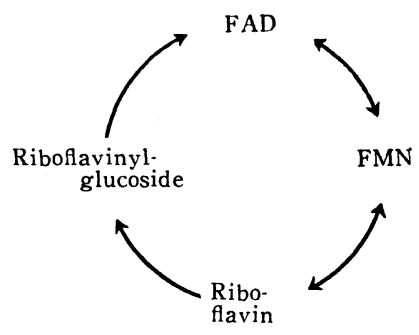

Fig. 3 Metabolism of Ribo flavin in the Body of a Mouse

\section{SUMMARY}

1. The unknown spot appearing in paper chromatograms of the whole body homogenates of mice is ascertained to be riboflavinyl-glucoside, with reference to absorption spectrum, $R_{\mathrm{F}}$ values using various solvent systems and the detection of glucose in the solution of riboflavinyl-glucose.

2. It was found that the body of a mouse contains only FMN and FAD, but no riboflavin and that riboflavin does not degrade in the body.

3 . In the course of 24 hours after loading with riboflavin plus ATP, it was found that the courses of $\mathrm{FAD}$ and of riboflavinyl-glucoside are roughly parallel, that the amount of $\mathrm{FAD}$ was greatest when the glucoside was loaded, that the amount of FAD was increased with the increase of the glucoside and that the loading of FAD in vivo resulted in the increase of FMN alone.

4. From the above findings, the phosphorylation process could be explained by the process : riboflavin $\rightarrow$ riboflavinyl-glucoside $\rightarrow$ FAD $\leftrightarrow$ FMN $\leftrightarrow$ riboflavin (in which ATP participated), since FMN alone was obtained in vivo by the decomposition of FAD. 


\section{ACKNOWLEDGMENT}

The author wishes to thank Dr. Saburo Watanabe, President of the Hospital, for his kind guidance.

\section{REFERENCES}

1. Whitby, L. G., Biochem. J., 50, 433 (1952).

2. Whitby, L. G., ibid. 52, 390 (1954).

3. Yagi, K., Newest Method of the Determination of Vitamins (Jap.) p. 43, Ishiyaku, Tokyo (1954).

4. Fujita, A., Method of Determination of Vitamins (Jap.) p. 298, Nankodo, Tokyo (1955).

5. Hunnekens, F.M., J. Am. Chem. Soc., 75, 3611 (1953). 